\title{
Examining Pre-service Science Teachers' Pedagogical Content Knowledge Through Lesson Study
}

\author{
Teresa Conceição $^{1 *}$ (D), Mónica Baptista ${ }^{1}$ (D) , João Pedro da Ponte ${ }^{1}$ \\ ${ }^{1}$ Instituto de Educação, Universidade de Lisboa, PORTUGAL
}

Received 11 July 2021 - Accepted 25 November 2021

\begin{abstract}
This investigation adjusted the lesson study (LS) model for the initial teacher education aiming to examine its effect in the development of the pre-service teachers' pedagogical content knowledge (PCK) namely, both their knowledge and understanding on how to transform a science topic to make it more understandable for the students. The LS topic was the speed of sound that is taught in the $8^{\text {th }}$ grade. The PCK construct was evaluated, as well as and in terms of both PCK-topic specific knowledge and PCK-pedagogical knowledge. The participants on this investigation were three pre-service teachers. The data were collected through video recording of LS sessions. The qualitative data collection was combined with quantitative and qualitative analysis procedures. The results showed that the LS promoted an improvement on pre-service teachers' PCK as well as in most of the aspects of both PCK-topic specific knowledge and PCK-pedagogical knowledge. PCK's aspect' 'Strategies for pupil self-evaluation' has not improved satisfactorily. These findings suggest that LS should be carried out during the training programs of the science PSTs.
\end{abstract}

Keywords: pedagogical content knowledge, pre-service teachers' training, professional development, lesson study, science teacher education, speed of sound

\section{INTRODUCTION}

High-quality education is crucial to provide young people with the required knowledge, attitudes and practices towards the Sustainable Development covering the three dimensions - economic, social, and environmental - set out in the United Nations Sustainable Development Agenda 2030. Students' learning is influenced by teachers' knowledge and performance in the classroom (National Commission on Teaching \& America's Future, 1996). Thus, teachers need a robust and continuously renewed professional knowledge to be able to deal with the challenges that emerge in the classroom. Then it is important to stimulate the teachers' pedagogical content knowledge (PCK) since their initial training (Baumert et al. 2010; Kind, 2009, 2017; Nilsson \& Loughran, 2012).

Teachers use PCK as a tool to make a topic more understandable, relevant, and captivating to the students (Grossman, 2010; Shulman, 1986). Teachers reveal PCK for a given topic when they are able to engage learners, with diverse interests and abilities, by relating the topic concepts with others, using different topic's representations or adapting the teaching approach (Shulman, 1986). However, the PCK might be somehow tacit (Korthagen \& Kessels, 1999) or hidden (Baxter \& Lederman, 1999) thus, being difficult to collect evidences of this knowledge during the teacher professional activities (Schön, 1983). Loughran, Mulhall and Berry (2004) proposed a tool to capture and portray the science teachers' PCK.

Although, there is not yet a consensual conceptualization of the PCK among the scientific community (e.g., Gess-Newsome et al, 2019; Kind, 2017; Kind \& Chan, 2019; Liepertz \& Borowski, 2018) it is widely accepted that it includes the content knowledge (CK) and pedagogical knowledge (PK) (Gess-Newsome et al., 2019; Loughran et al., 2004; Shulman, 1986).

The literature survey shows that the PCK involves planning a well-crafted lesson and its improvement based on students' performance after being implemented. The PCK is personal as well as specific for a given topic and a target group of students regarding their grade and social context (Carlson \& Daehler, 2019;

(c) 2022 by the authors; licensee Modestum. This article is an open access article distributed under the terms and conditions of the Creative Commons Attribution License (http://creativecommons.org/licenses/by/4.0/). 


\section{Contribution to the literature}

- Lesson study in the initial training improved the PCK of the pre-service teachers

- Pre-service teachers' PCK-TSK improved significantly and PCK-PK, in general, also improved when they were involved in a lesson study

- Lesson study shows potentialities to be used in the initial teacher education

- This research increments the knowledge on the pre-service teachers' PCK through lesson study

Gess-Newsome, 2015; Lederman \& Gess-Newsome, 1992). These teachers' practices are pertinent during the initial teacher training since they provide opportunity for pre-service teachers (PSTs) both to apply what they have formally learned in the university and to reflect on the teaching-related experiences (section PCK in initial teacher education) (e.g., van Driel \& Berry, 2012).

However, PSTs need guidance towards a deeper understanding about students' ideas, as well as promotion of discussions about student results and possible reasons behind students' difficulties (Käpylä et al., 2009). Moreover, PSTs tend to value the teachercentred approach and prefer to promote students work individually solving closed tasks (Uşak, 2009).

Since, the lesson study (LS) is a student-centred teacher professional development model typically used for in-service training (Fujii, 2016; Stigler \& Hiebert, 1999), if adjusted to the initial teacher education it is potentially effective to develop PSTs pedagogical approaches including student-centred lesson plans and tasks (Juhji \& Nuangchalerm, 2020).

The present investigation aims to evaluate the effect of the LS in the development of PSTs' PCK on the speed of sound, at $8^{\text {th }}$ grade. More specifically the research questions (RQ) are:

RQ1: Which is the effect of the LS - adjusted for the initial teacher education - in the development of the PCK on the speed of sound at $8^{\text {th }}$ grade for each PST?

RQ2: Which are the changes in the PCK on the speed of sound for each PST?

\section{RESEARCH SCOPE}

\section{PCK in Initial Teacher Education}

The literature survey shows that teachers' PCK has a positive effect on the instructional quality and on the student progress (e.g., Baumer at al., 2010; Coe et al., 2014). Thus, it is important to stimulate the PCK since the initial teacher training (Kind, 2017; Sorge at al., 2017). It is generally accepted among researchers the importance of the classroom practices to evolve PSTs' PCK (e.g., Gess-Newsome, 2015; Grossman, 2010) including, the discussion of the teaching strategies to help students to overcome their learning difficulties (de Jong \& van Driel, 2004; Nilsson \& Karlsson, 2019).
In addition, there is a strongly held expectation that the initial training is an opportunity for PSTs to model their teaching practice by cooperating teachers' (CT) observation (e.g., Clarke et al., 2014). In this way, CT offers PSTs (i) with important images of the teaching practice (Seperson \& Joyce, 1971), (ii) practical knowledge that is rather new to PSTs, namely the CTs' personal teaching theories, and (iii) theory - practice integration (Zanting et al., 1998). The CT's role is more effective if he jointly plans, teaches, and analyses lessons with the PSTs as well as when the CT explicit their thinking and reflections about their own teaching during discussions with the PSTs (Zanting et al., 1998). A research performed with pre-service chemistry teachers also corroborated these results by revealing that the experienced teachers expanded PSTs descriptions about students' difficulties and misconceptions as well as enriched their knowledge of instructional strategies (Van Driel et al., 2002).

As the PCK is a key variable in quality teaching and as has already been mentioned it might be somewhat tacit or hidden (section Introduction), its assessment is important for both teacher education researchers and teacher educators. This required to model this construct into structuring components. This investigation adopted the two components, PCK-content knowledge and PCKpedagogical knowledge, identified by Gess-Newsome et al. (2019) as follows:

1. PCK-content knowledge, henceforward named PCK-topic specific knowledge (PCK-TSK), refers to the accurate knowledge of the scientific concepts to make a topic more understandable to the students, including Nature of Science (NOS) and the use of representations

2. PCK-pedagogical knowledge (PCK-PK) refers to the understanding of:

- How students' prior conceptions determine the instructional decisions

- The relationship between the adopted teaching strategies and the students learning

- Implications of the teaching strategies based on students results

- Strategies' identification to promote student examination of their own learning

Sawada et al. (2002) and Loughran et al. $(2004,2012)$ proposed tools to evaluate PCK-TSK and PCK-PK. 
Sawada et al. (2002) designed and validated an instrument containing 25 items to evaluate mathematics and sciences teaching practices. This instrument was based on the recommendations and standards promulgated by professional societies of mathematicians, scientist, and educators. Loughran et al. (2004, 2012) developed a tool for accessing science teachers' PCK. This tool transforms the tacit knowledge into explicit forms of evaluating science teachers' understanding of specific aspects of the PCK.

\section{Lesson Study for Developing PCK}

The goal of the LS is to improve the teaching of a specific topic based on the students learning and reasoning, typically, implemented with a small group of teachers (Fujii, 2016; Stigler \& Hiebert, 1999). The LS model was developed in Japan based on its schoolwork cultures and teacher professionalism but has already been adjusted for other cultural contexts and it has been mainly used in the long-life teacher training (e.g., Coenders \& Verhoef, 2019; Huang \& Shimizu, 2016; Lim et al., 2016; Perry \& Lewis, 2009). However, its application to the initial teacher education had a growing interest by the scientific community in the last decade (e.g., Larssen et al., 2018; Ni Shuilleabhain \& Bjuland, 2019) revealing promising results (e.g., Marble, 2007; Munthe et al., 2016). Research studies on the applicability of the LS during the initial teacher education needs to be better understood. The LS might comprise cycles that in turn encompasses phases namely, the 1st cycle includes the lesson planning, the Research Lesson and the Lesson Reflection whereas the following cycles include an improved Research Lesson and the Lesson Reflection phases. The relative relevance of the LS phases is non-consensual. Hart et al. (2011) viewed the planning phase as the most challenging. Akerson et al. (2017) stated the reflection phase as the responsible for enhancing PSTs' PCK. Whereas, Nilsson (2008) and van Driel et al. (2002) found the actual classroom teaching, as the fundamental source for developing PSTs' PCK, although this conclusion was not achieved within the scope of a LS.

Furthermore, is not consensual among researchers and scholars, the number of cycles that a LS should comprises. Fujii (2014, 2016, 2018) interrogates the pitfalls of emphasizing re-teaching in a LS implementation. Indeed, this investigation (Fujii, 2014) considers that the purpose of the LS is not to achieve a perfect lesson plan. Instead, the LS goal is to gain new knowledge for teaching and learning. In fact, Takahshi and McDowel (2016) also identified, in the literature, some misunderstanding concerning the LS purpose as a process to obtain a perfect lesson plan.

Besides this controversy, the research studies on the applicability of the LS during the initial teacher education seem to encourage the implementation of more than one cycle, in this context (e.g., Akerson et al.,
2017; Can, 2019; Danday, 2019; Jain \& Brown, 2020; Juhler, 2016; Marble, 2007). In this scope, Akerson et al. (2017) used a case study approach focused on the Research Lessons and post Reflections phases of the LS to investigate the PCK improvement of the PSTs to teach the NOS, at the primary level. The authors concluded that although the PSTs were not able yet to include NOS connections within their own lessons, after their participation in the LS they were able to provide feedback to their peers regarding how to include NOS in their Research Lessons. Whereas, Juhler (2016) assessed the effect, and the success, of the lesson planning phase of the LS combined with a Content Representation tool to start developing PSTs' PCK. The author also concluded that PSTs became more focus on students' difficulties and misconception as well as on students' preferences or assessment, rather than on students' behaviour. Can (2019) also used a case study approach to investigate PCK improvement of three PSTs on the topic heat and temperature. In his investigation, the lesson plan consisted on a Content Representation tool prepared by the PSTs and improved just before the Research Lessons. The researcher concluded that the PCK 'knowledge of curriculum', 'knowledge of students' and 'knowledge of instructional strategies' significantly improved, but not the 'science teaching orientations', nor the 'knowledge of assessment'.

This research contributed to deeper the knowledge of PCK of PSTs in two senses:

- from the science educators' perspective since it highlights the feasibility of including the lesson study in the initial teacher programs;

- from the researchers' perspective since it concurs to increment the academic knowledge on the PCK development using lesson study in initial teacher education.

\section{METHODOLOGY}

\section{Participants' Characterization}

The participants of this investigation were three science PSTs, Identified in this paper as PST1, PST2, and PST3. The PSTs have an undergraduate degree (3 years) in chemistry. By the time this investigation was performed, all participants were students enrolled in the first year of their teacher preparation programme (duration of two years in total). The PSTs identities are not revealed since they are not relevant for the conclusions of the study.

The PST1 (42 years old) taught in a private school (less than two years), whereas, both PST2 and PST3, (35 and 34 years old, respectively), had some experience as students' tutoring in private study centers. The participants were recruited to participate in this investigation on a voluntary basis by the university science teacher educator who was also involved in this 
Table 1. Organization of the lesson study (Conceição et al., 2019)

LS's Cycles Description of the sessions' content

Cycle 1 (ten

Exploratory study (Sessions 1-6)

sessions) 1. Identification of the content topic (i.e., speed of sound) and how this is explored in the curriculum, reference documents and textbooks.

Student conceptions about the content topic (analysis of scientific articles)

2. Discussion of the level of challenge and openness of tasks in IBSE (the nature of tasks)

3. Completion of different tasks on various content topics, focusing on learning objectives, possible student reasoning and difficulties. Discussion of everyday contexts

4. Completion of different tasks on various content topics. focusing on learning objectives, possible student reasoning and difficulties. Discussion of everyday contexts (conclusion)

5. Development of the diagnostic task on the concepts of distance, time interval and speed

6. Analysis of the students' results in the diagnostic task. Identification of the students' learning progress and difficulties. Analysis of the transcription of a lesson in three stages (Introduction the task, students' autonomous work and collective discussion/synthesis) and of the communication promoted by the teacher in the classroom during these stages (questioning and collective discussion)

Lesson Planning (Sessions 7-8)

7. Completion of a set of tasks in IBSE on the topic. Discussion of contexts. learning objectives, possible reasoning and difficulties of the students. Development of the research lesson task (i.e., topic task) and context selection. Focusing on the IBSE, the task allows students to interpret and represent information, to build and use problem-solving strategies, to explain a phenomenon, to make predictions, to generalise and to communicate the results to the class. The inquiry task is applied in a 45 minute lesson. Students work in groups and are encouraged to solve the task autonomously. The task context is the thunderstorm phenomenon

8. Development of the research lesson plan based on previous work Research Lesson 1

9. PSTs' observed the Research Lesson and filled in the lesson observation guide Lesson Reflection 1

10. PSTs analysed students' performance and reasoning and discussion of strategies to improve student learning. PSTs supported their analysis in the students written productions (task solved), the filled in observation guides. videotapes of the Research Lesson. Thereafter, the PSTs improved the lesson plan and the students' task as well as adjusted the observation guide to be used in the next cycle

Cycle 2 (two sessions)
Research Lesson 2

11. PSTs' observed the improved Research Lesson 1 taught to another class and filled in the unproved observation guide

Lesson Reflection 2

12. PSTs analysed the implication of the improved lesson plan and task in the students' performance (using the same sources used in Reflection 1) investigation. This university science teacher educator offers the science teacher trainee and certification. The CT provided the information about the 8th grade students involved in LS. PSTs already knew from the previous semester the CT also as cooperating teacher of their initial training process (i.e., not in the scope of this investigation).

The previous syllabus of the program on science teaching provided to the PSTs the PCK construct.

\section{Design and Conduction of the Lesson Study}

The topic of the LS conducted in the presented investigation was the speed of sound, included in the syllabus of the discipline of physics and chemistry offered at grade 8 (ages between 14-15 years old). There is a concern that materialistic thinking-meaning the tendency to attribute a set of matter-like properties to non-matter concepts - is one of the central barriers that students face in the journey toward understanding the sound concept (Eshach et al., 2017). Indeed, materialistic thinking occupies a central place in the nonscientific "naïve thinking" with which students enter into scientific instruction, and that it is a barrier students need to overcome in the process of conceptual change (Eshach \& Schwartz, 2006).

The LS comprised two cycles organized as described in Table 1 (also depicted in Figure 1), of which the 1st cycle encompasses 10 sessions and the 2 nd cycle, two sessions. Thus, in total the LS comprised 12 sessions lasting for $2 \mathrm{~h} 30 \mathrm{~m}$ each except the two Research Lessons that lasted 45 minutes each and that took place at the school where the CT works. The 1st cycle comprised the 'Exploratory Study' (sessions 1 to 6), the 'Lesson Planning' (sessions 7 and 8), the 'Research Lesson 1' (session 9) and the 'Lesson Reflection 1' (session 10). The $2^{\text {nd }}$ cycle consisted only in the 'Research Lesson 2' (session 11) and 'Lesson Reflection 2' (session 12). The content of each session is summarized in Table 1. 


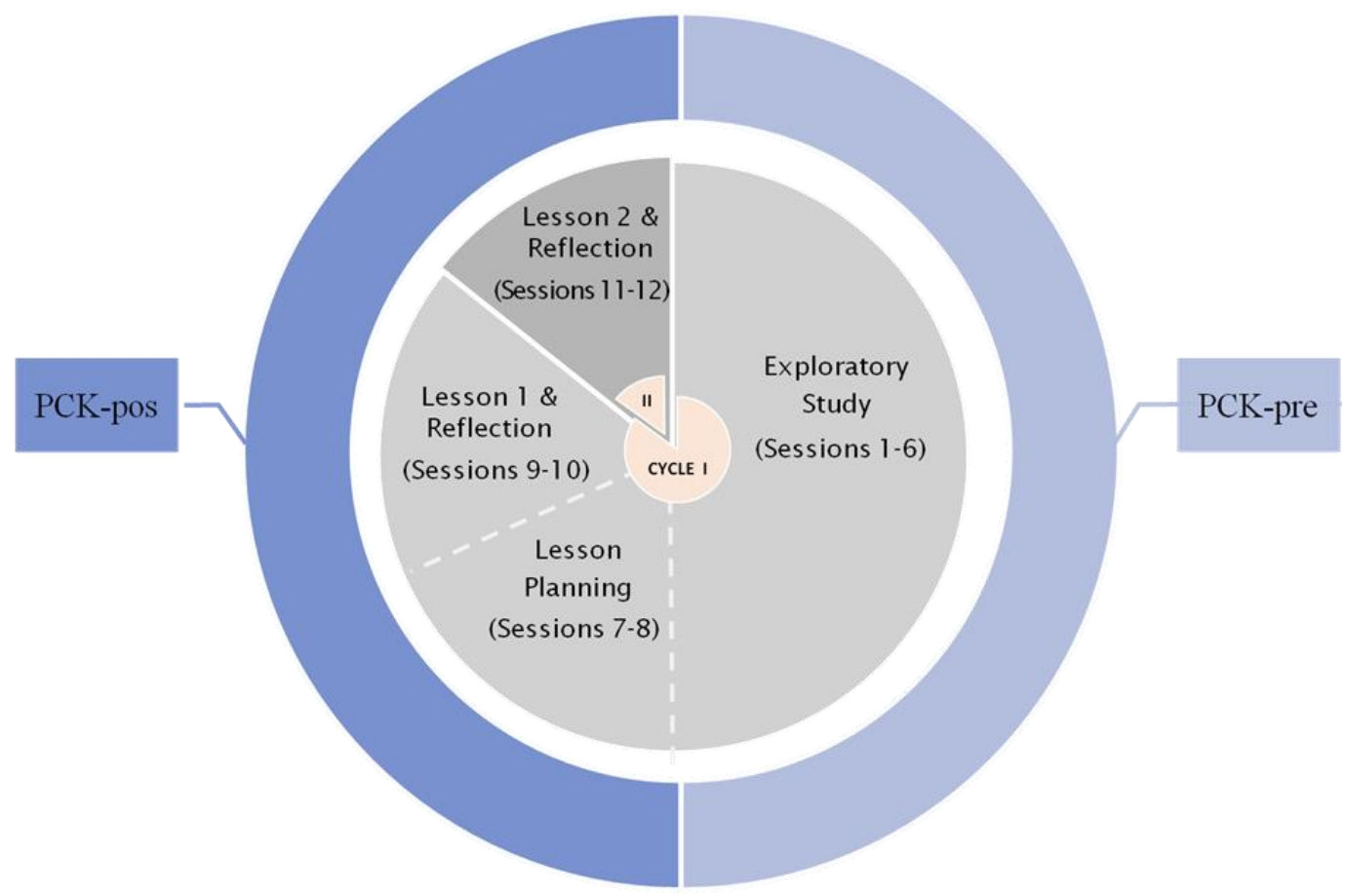

Figure 1. Cycles and sessions of the lesson study as well as data source to evaluate previous Pedagogical Content Knowledge (PCK-pre) and post Pedagogical Content Knowledge (PCK-pos) for each pre-service teacher

During this investigation, three researchers participated in the LS, of which one is a science education expert. The science educator presented the LS theory and supported PSTs' learning throughout the Exploratory Study of the LS (sessions $1-6$, Table 1). This support was guided through an inquiry based strategies. PSTs' learning was also supported on inquiry approach by the other two researchers.

- Taking into consideration the beneficial role of a $\mathrm{CT}$ in the PSTs education (as previously mentioned, section PCK in initial teacher education), the LS integrated a CT with previous background as CT and with twenty years of experience as science teacher. The $\mathrm{CT}$ taught the Research Lessons (sessions 9 and 11, Table 1). Throughout the LS, the CT and the PSTs expressed their own thinking on the teaching of the topic and on students' learning, as well as how to improve students' results and why. All researchers collected the data through field notes in all LS sessions. They also supported PSTs analyse of the students' responses on the task they performed during the research lessons, namely conjecturing what might was behind the students' difficulties. In the LS sessions, the PSTs played the role of students and were the first to intervene in the group.

\section{Data Collection}

The data was collected through video recording of all sessions and participating observation by two of the authors of the present paper. To collect the data, two of the authors of the present manuscript used a form consisting of the 25 subcategories proposed by Sawada and colleagues (2002), adjusted to the nature of the activities in which the PSTs were involved in the research. For example, since the PSTs did not teach the research lessons the question included in the Sawada's instrument "students were involved in the communication of their ideas using a variety of means and media", was adjusted to: "in the planning of research lessons and reflection sessions, event are created for students to engage in communicating their ideas using a variety of means and media". During the sessions, two of the authors used the form to collect the data. This data consisted in segments of text related to the subject of each subcategory of the form. Thus, immediately after each session, the two authors completed together the information that each of them gathered to collect. In addition, all sessions were videotaped (27 hours in total) and, then, transcribed. These transcripts were also used to complete the prefilled form. This procedure was repeated for all sessions of the LS.

The research study consisted of evaluating the effect of the LS on PCK on the speed of sound of each PST. Thus, the LS is the intervention that might (or not) have impact on PCK of the PSTs. The answer to the RQs required the comparison between the PSTs' PCK before and after the LS intervention. However, before the LS, the PSTs had no enough knowledge to elaborate a detailed lesson plan and an inquiry task based learning with multiple representations for the students. As such, the present investigation adopted the first six sessions of 
the LS to explore the dimensions of the lesson plan proposed by Robak et al. (2006) and inquiry tasks that teacher may use in the classroom, as well as to collect data after this Exploratory Study (Table 1). Thus, in this investigation, the PCK of the PSTs' before participating in the LS, designated hereafter as PCK-pre, was evaluated using the data collect from sessions 1 to 6 , whereas the PCK of the PSTs after the LS intervention, designated hereafter as PCK-pos, was evaluated from data collected during sessions 7 to 12 . Figure 1 systematises the LS organization in terms of cycles and sessions (detailed in Table 1) as well as the sessions that were the data source to determine the PCK-pre and PCKpos, for each PST.

\section{Data Analysis}

The qualitative data collection was combined with quantitative and qualitative analysis procedures (Creswell, 2002). The qualitative approach comprised the construction of the codification matrix (detailed below) and the data codification, which are the primary results. The primary results were then analysed qualitatively and quantified in a qualitative ordinal scale, which are the secondary results. The secondary results were analysed statistically to answer RQ1 and transformed to answer RQ2. The methodology of the data analysis is schematically represented in the Graphical Abstract.

\section{Codification matrix}

The codification matrix for the data analysis was designed adopting as categories (Table 2) the seven aspects of the both PCK-TSK and PCK-PK components proposed by Gess-Newsome and colleagues (section PCK in initial teacher education). In addition, the 25 subcategories proposed by Sawada and colleagues (section PCK in initial teacher education) were successively reformulated until being adjusted to the

Table 2. Codification matrix of Pedagogical Content Knowledge - Topic Specific Knowledge (PCK-TSK) and of Pedagogical Content Knowledge -Pedagogical Knowledge (PCK-PK)

\begin{tabular}{ll}
\hline Coding categories & Coding subcategories \\
\hline PCK- A1 Depth, breadth, and accuracy & 1. Core concepts in the teaching the topic
\end{tabular}

TSK of topic knowledge 2. Variables that support the core concepts for teaching of the topic

3. Syllabus in the teaching of the topic

A2 Connection with the nature of 4 . Students' own methods of solving the task/problems

science (NOS) 5. Intellectual rigor, constructive criticism and challenging ideas in the topic's learning

6. Students interpret data

A3 Fluency with multiple modes 7. Elements of abstraction/representations of representation

8. Connection with real world phenomenon with the topic teaching

PCK-PK B1 Understanding how students' 9. Students' previous conceptions

prior conceptions determine the 10 . Students' previous ideas that might determine the progress of the instructional decisions lesson

B2 Rational linking teaching 11. Students build a shared knowledge

strategies to student learning 12. Students' learning autonomy

13. Students' communication (making presentation, brainstorming, critiquing, listening)

14. Divergent modes of students' thinking

15. Students' work between and among students

16. Students' contributions that might determine the classroom communication

17. Respect for what others had to say

18. Motivation of the students in the learning process

19. Patient with students' divergent ideas (is not the same thing as

tolerating unwanted student behavior or unexpected)

20. Teacher is a resource person, working to support and enhance student learning. The metaphor "guide on the side" is in accord with this item

B3 Implications of teaching 21. Students' results in the use of representations or elements of abstraction strategies based on students' and implication in the teaching of the topic results

22. Students' results with real world phenomena and implication in the teaching of the topic

23. Students' results about formulating conjectures/hypotheses before collecting data and calculations and implication in the teaching of the topic

24. Students' difficulties in the interpretation of the questions of the task and implications

B4 Strategies to promote students' 25 . Students evaluate their own learning examination of their own learning 
Table 3. Rationale to quantify the Units of Analysis of the coding subcategory ' 1 . Core concepts in the teaching the topic' Scores Rationale

0 The data do not reveal evidences that the PST knows "what" core science ideas/concepts are important to teach the topic to a specific group of students

1 The data reveal an evidence that the PST knows "what" core science ideas/concepts are important to teach the topic to a specific group of students. This knowledge was designated as "factual PCK"

2 If data reveal evidences (i.e., two or more) of "factual PCK"

3 The data reveal evidences that the PST knows "how" to transform the core science ideas/concepts of the topic to become more understandable and captivating to a target group of the students. This knowledge was designated as "procedural PCK"

The data reveal evidences that the PST knows "why" the core science ideas/concepts are important for the topic teaching for a group of students. This knowledge was designated as "conditional PCK"

nature of the activities in which PSTs were involved during the LS (section Lesson Study for developing PCK). The subcategories were then clustered in the corresponding categories using a qualitative (deductive) method and codified from 1 to 25 , as presented in Table 2.

\section{Mixed data analysis}

After the transcription, the data were analysed and segmented according to the 25 subcategories, using a content analysis method (Krippendorff, 1980). The Unit of Analysis was the segment of text containing an evidence of PCK of a given PST. The Units of Analysis that were difficult to code were discussed by two of the researchers (authors). If no consensus was reached, Units of Analysis were re-segmented or neglected.

Thereafter, the Units of Analysis were qualitatively analyzed according to Loughran's et al. (2004) approach to disentangle the PCK factual (what), procedural (how), and conditional (why). The quantification of the Units of Analysis - secondary results - was expressed in a qualitative ordinal scale from 0 to 4 following the rationale exemplified for the coding subcategory ' 1 , Core concepts in the teaching the topic' in Table 3.

The PCK consists of 25 items, i.e., 25 subcategories (Table 2). Each subcategory is scored on a scale of 0 to 4 points, as already mentioned. The median PCK-pre and PCK-pos values were computed for each of the PST. The median of the PCK-pre and PCK-pro for each PST's was calculated as follows:

- The scores assigned to the 25 subcategories, for each PST, were sorted in ascending order

- Since $n=25$ is odd, the median corresponds to the score value at position $(n+1) / 2$, i.e., in this case, to the value at position 13 .

The PCK-pre and PCK-pos, for each PST, were used to answer to Research Question 1 (RQ1).

As proposed elsewhere (Gess-Newsome et al., 2019) in order to mitigate possible biased analysis, the Units of Analysis were scored by two participant observers. Accordingly, one of the participant observers scored all the Units of Analysis, and another scored 25\% of them, randomly selected from all subcategories. Since the inter-rater reliability achieved was 0.80 the required accuracy was assured (Cohen, 1960).

\section{Quantitative approach to answer Research Question 1}

The approach of quantitative data analysis to answer RQ1 consisted of the statistical treatment of the secondary results namely, PCK-pre and PCK-pos. In concrete, the effect that the lesson study (adjusted for initial teacher education) had on each PST in teaching the speed of sound was assessed through 25 subcategories related with PCK in that were evaluated before and after the lesson study to compute PCK-pre and PCK - pos, respectively (Figure 1). The median values of the score obtained by each PST in the 25 items before and after of the LS intervention were analysed globally by a descriptive statistical treatment.

\section{Qualitative approach to answer Research Question 2}

The evaluation on the changes in the PCK on the speed of sound for each PST (RQ2) required identifying changes in PCK-pre and PCK-pos in each category (A13 and B1-4, in Table 2). As such, to evaluate the changes in PCK for each category, it was determined, and analysed, the median of the secondary results for the corresponding subcategories before and after of the LS intervention.

\section{RESULTS}

\section{Answer to the Research Question 1}

This investigation aimed to examine the effect of the LS in the development of the PCK of PSTs on the speed of sound to 8th grade students (RQ1). Table 4 summarizes the results of the median of the PCK-pre and PCK-pos for each PST, determined as referred in section Data analysis methodology.

All PSTs exhibited a PCK-pre of 2 whereas the PCK pos was 4, for PST1 and 3, for both PST2 and PST3 indicting that the PCK of the PSTs on the speed of sound at 8 th grade in a specific classroom context, and with lessons lectured by the CT improved (section Design and conduction of the lesson study). 
Table 4. Median of previous Pedagogical Content Knowledge (PCK-pre) and post Pedagogical Content Knowledge (PCKpos), i.e., PCK before and after the lesson study implementation, for each pre-service teacher (PST)

\begin{tabular}{lcc} 
& PCK-pre (median) & PCK-pos (median) \\
\hline PST1 & 2 & 4 \\
PST2 & 2 & 3 \\
PST3 & 2 & 3 \\
\hline
\end{tabular}

Table 5. Examples of results scored for previous Pedagogical Content Knowledge (PCK-pre) and post Pedagogical Content Knowledge (PCK-pos), i.e., PCK before and after the lesson study implementation

\begin{tabular}{|c|c|}
\hline & Examples of results scored for PCK-pre an \\
\hline \multirow{12}{*}{$\begin{array}{l}\text { "Core } \\
\text { concepts for } \\
\text { teaching and } \\
\text { learning the } \\
\text { topic" }\end{array}$} & PCK-pre: We realized that the students \\
\hline & knew to calculate the distance and the \\
\hline & time interval of the speed of a ball. Thus, \\
\hline & I assumed that it would be easy for them \\
\hline & to apply for the context of the sound... \\
\hline & $\begin{array}{l}\text { that is only a ratio, that's all (PST1, video } \\
\text { recording) }\end{array}$ \\
\hline & Interpretation: The score in terms of PCK \\
\hline & pre was 2 (factual knowledge) (Table 3) \\
\hline & because PST1 revealed not knowing how \\
\hline & to do with the core concepts of the topic, \\
\hline & since the context of sound is much more \\
\hline & $\begin{array}{l}\text { complex to explore than the context of a } \\
\text { macroscopic object such as a ball. }\end{array}$ \\
\hline
\end{tabular}

PCK-pos: Now, after observing the students I realize that this topic is more complex than I considered. Changing from the context of a ball to the context of sound involves a high degree learning the I assumed that it would be easy for them of students' abstraction. This is not easy, not easy at all. Thus, I topic" to apply for the context of the sound... ended up by agreeing that the concepts that the students that is only a ratio, that's all (PST1, video already knew about distance, time interval and speed were a good starting point to understand the concepts of the topic (PST1, video recording).

Interpretation: The score in terms of PCK- Interpretation: Our score in terms of PCK-pos was 4 (conditional pre was 2 (factual knowledge) (Table 3) knowledge) (Table 3). In fact, PST1 knows that the concepts of 列 integrally related to and constitutive of other concepts. The speed of sound showed to be a challenging topic for the students, since understanding the concepts, speed of the sound, distance between the source and receptor and time interval of the sound propagation require a highly level of abstraction because they cannot see the sound, as PST1 noticed.

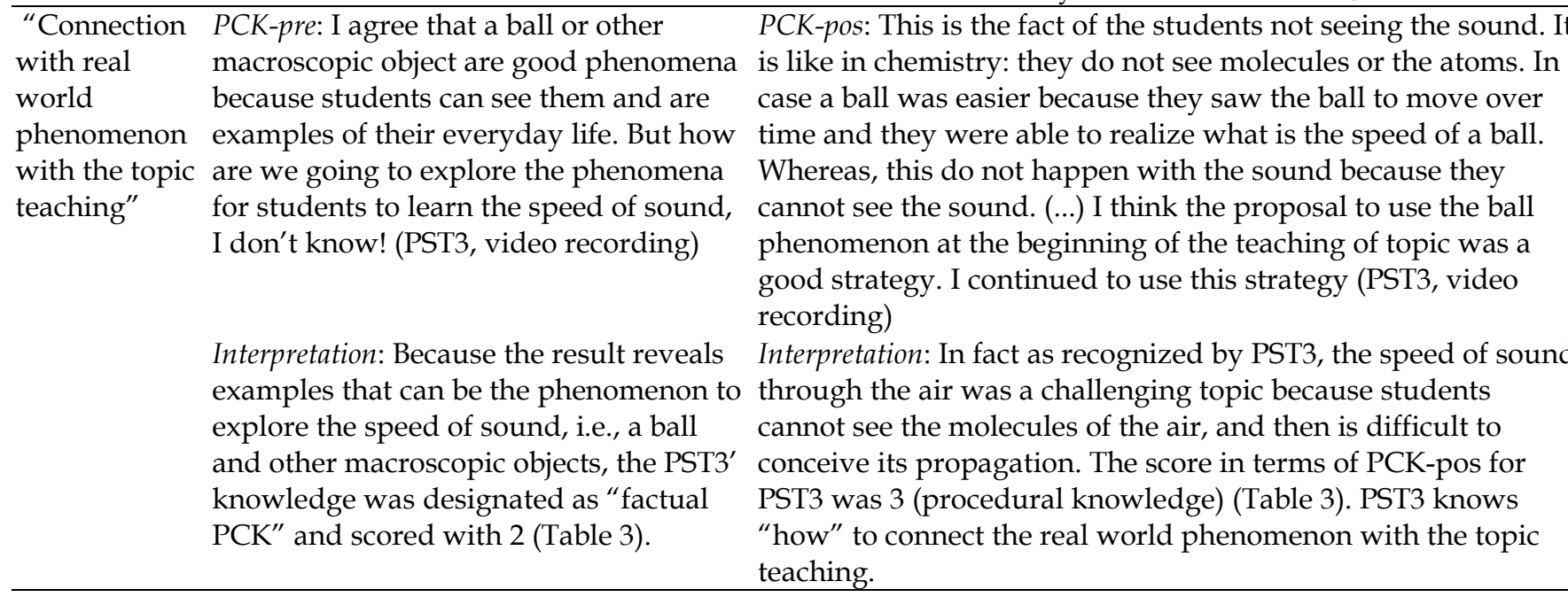

These results support the answer to the RQ1 of this investigation i.e., the LS actually contributes to the overall improvement of PCK of the PSTs. This means that before the LS the PSTs' PCK-pre on the speed of sound, to $8^{\text {th }}$ graders, was factual (median $=2$ for each PST) whereas after the LS, the PCK-pos(median) increased to values 3 (for PST2 and PST3) and 4 (for PST1) revealing a procedural or conditional PCK-pos in many of the situations addressed in the LS. As such, the LS contributed to the PSTs' PCK improvement.

Table 5 presents some video recordings' extracts of results scored for PCK-pre and PCK-pos according the rationale in Table 3 .

\section{Answer to the Research Question 2}

The answer to the RQ2, i.e., which are the changes in the PCK on the speed of sound for each PST, required the comparative analysis of the median of the distinct aspects of both the PCK-TSK and PCK-PK (as presented in the column 2 of Table 2), before and after the LS. Table 6 presents the PCK-TSK and PCK-PK values, together with schematic representation, for each aspect, before and after the LS.

\section{PCK-TSK aspects}

Table 6 shows that for the three aspects of PCK-TSK (A1-3), of each PST, the median values were 2, before the LS intervention, and, 3 or 4 after that. This means that 
Table 5 (continued). Examples of results scored for previous Pedagogical Content Knowledge (PCK-pre) and post Pedagogical Content Knowledge (PCK-pos), i.e., PCK before and after the lesson study implementation Examples of results scored for PCK-pre and PCK-pos

\begin{tabular}{|c|c|c|}
\hline $\begin{array}{l}\text { "Students' } \\
\text { previous } \\
\text { conceptions" }\end{array}$ & $\begin{array}{l}\text { Interpretation: Because the example above } \\
\text { reveals evidence that PST } 2 \text { knows that } \\
\text { students' previous understanding about } \\
\text { distance is important for the teaching the } \\
\text { topic, PST2' knowledge was designated } \\
\text { as "factual PCK" and scored with } 1 \\
\text { (Table 3). }\end{array}$ & $\begin{array}{l}\text { PCK-pos: I consider that the strategy of starting from what } \\
\text { students already know about the distance, time interval and } \\
\text { speed of a ball was useful. And it was from his understanding } \\
\text { of these concepts that we develop the task of the research } \\
\text { lesson and the lesson plan. (...). The concept of speed is } \\
\text { difficult for students in grade } 8 \text {. For me, this is the most } \\
\text { difficult concept and the one that should be emphasized in } \\
\text { teaching the speed of sound (PST2, video recording). } \\
\text { Interpretation: This example above reveals evidences that PST2 } \\
\text { already knows that students' prior knowledge of speed should } \\
\text { receive special attention from the teacher, as students have } \\
\text { difficulty understanding the speed of sound. PST2 knows } \\
\text { "how" the students' previous conceptions should be included } \\
\text { in instructional decisions, this knowledge was designated as } \\
\text { "procedural PCK" and scored with } 3 \text { (Table } 3 \text { ). }\end{array}$ \\
\hline
\end{tabular}

Table 6. Examples of results scored for previous Pedagogical Content Knowledge (PCK-pre) and post Pedagogical Content Knowledge (PCK-pos), i.e., PCK before and after the lesson study implementation

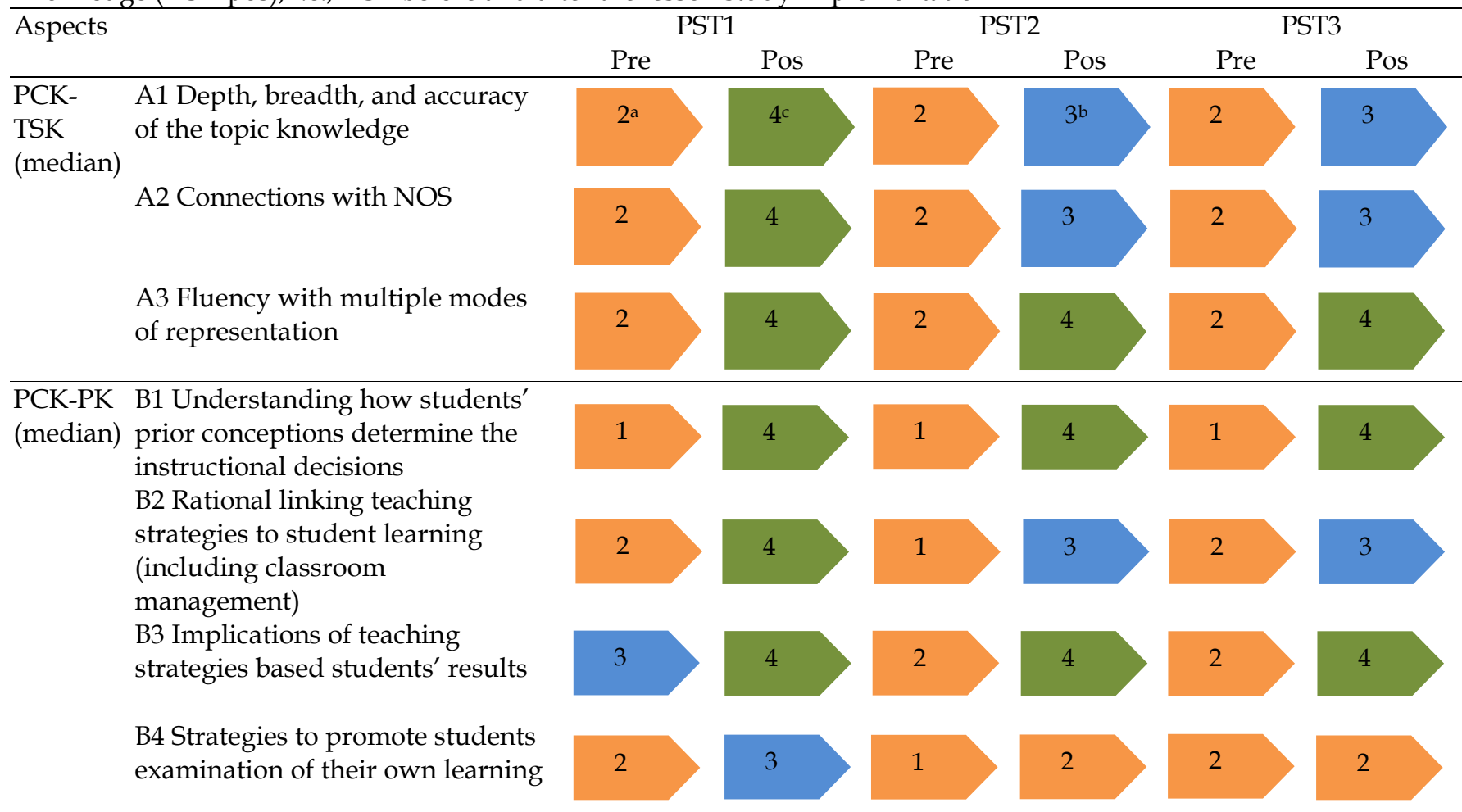

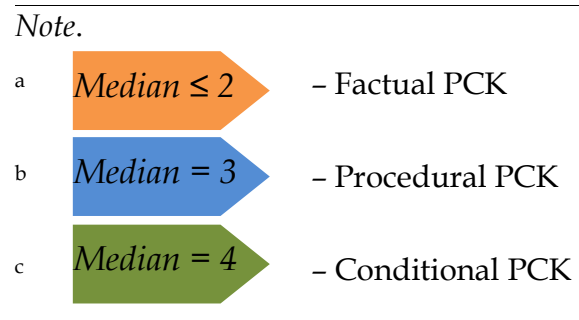

before to the intervention, the three PSTs' had factual knowledge to help a group of $8^{\text {th }}$ grade students to understand the topic regarding: Depth, breadth, and accuracy of the topic knowledge (A1), Connections with NOS (A2), and Fluency with multiple modes of representation (A3). Whereas, after the LS, the three
PSTs' already exhibited procedural or conditional knowledge for the three aspects of PCK-TSK. For example, regarding:

1. Depth, breadth, and accuracy of the topic knowledge (A1), before the LS, the PSTs did not have an 
integrated knowledge of the core concepts of the topic yet (median value $=2$ for each PSTs). Whereas after the LS, they already showed 'how to' use the topic variables (distance, time interval and speed) to anchor the topic concepts (distance, time interval and speed, of the sound propagation) (median values $=3$ or 4 )

2. Connections with NOS (A2), before the LS, the PSTs did not know how to include NOS elements in the lesson plan (e.g., PSTS did not elaborate open questions to promote students' own methods of solving the task) (median value $=2$ for each PSTs). Whereas after the LS, PSTs already suggested a challenging graph for students to use without the teacher support (median values $=3$ or 4)

3. Fluency with multiple modes of representation (A3), before the LS, the PSTs did not know how to explore the topic concepts with a real world phenomenon that corresponds to a factual knowledge (median value $=2$ for each PSTs). Whereas after the LS, PSTs already revealed to understand why it is important to use real world phenomena in teaching of the topic (median value $=4$ for each PSTs)

As such, the LS contributed to the PSTs' PCK-TSK improvement on the speed of sound at $8^{\text {th }}$ grade in a specific classroom context for all the aspects of the PCKTSK.

\section{PCK-PK aspects}

Table 6 shows that, the median values of the PCK-PK of each PST for the aspects, B1-3, before the LS intervention, were 1,2 or 3 . Whereas, after that, the median values became 3 or 4 . It means, before the LS intervention, the three PSTs' exhibited a PCK-PK factual or procedural on Understanding how students' prior conceptions determine the instructional decisions (B1), on Rational linking teaching strategies to student learning (including classroom management) (B2) and on Implications of teaching strategies based students' results (B3). Whereas, after the LS intervention the PSTs' PCK-PK improved to procedural or conditional in the three first aspects of the PCK-PK.

Regarding the PCK-PK' aspect Strategies to promote students examination of their own learning (B4), before the LS intervention, the median value was 2, for PST1, whereas after that, the median value became 3 . It means, before the intervention, the PST1' exhibited a PCK-PK factual to promote students examination of their learning, whereas after the intervention his knowledge improved to procedural. Concerning the PST2 and PST3, the PCK-PK in the last aspect (i.e., B4) their knowledge remained factual even after the LS intervention (median values 1 or 2 , before the interventions, and 2 after that).

For example, regarding:

1. Understanding how students' prior conceptions impact the instructional decisions (B1), before the LS intervention, based on the students' prior knowledge, the PSTs' revealed not know how to use students' previous conceptions in the lesson planning (median value $=1$ for each PSTs). Whereas, after the LS, all the PSTs included students' backgrounds and experience in their teaching strategies and revealed that they understood why it is important. Thus, PSTs developed a conditional knowledge (median value $=4$ for each PSTs)

2. Rational linking teaching strategies to student learning (including classroom management) (B2), before the LS intervention, although one of PSTs' main concerns was to promote rich and creative interactions in the classroom, all PSTs revealed not know how to implement it. As such, PSTs revealed factual knowledge (median values $=1$ or 2 ). Whereas after the intervention, the three PSTs valued group work in the classroom and demonstrated to understand the importance of students sharing and negotiating ideas while they learn which means that all PSTs developed procedural or conditional knowledge (median values $=3$ or 4 )

3. Implications of teaching strategies based students' results (B3), before the LS intervention, the three PSTs choose an appealing real world phenomenon to explore the concepts of the topic meaning that the PSTs had a factual or procedural knowledge (median values $=2$ or 3). Whereas, after the intervention, the PSTs reflected on the students' difficulties while they learned the topic with a real-world phenomenon, namely the thunderstorm, to recognize that this phenomenon was too complex for their target students to learn the speed of sound. As such, the PSTs' PCK-PK developed conditional knowledge (median $=4$ for each PST)

4. Strategies to promote students examination of their own learning (B4), was the only aspect of the PCKPK that not all the PSTs revealed an improvement. Namely, the PST1 evolved, from before to after the LS intervention, from identifying students' self-assessment strategies to know how to promote it in educational settings. However, PST1 did not reveal to understand why this is useful. Thus, this change suggests that PST1 improves from factual knowledge (mean value $=2$ ) to procedural (mean value $=3$ ) but did not achieve a deeper knowledge. While, both PST2 and PST3, although recognizing the benefits of the students' self-assess, PSTs were not able to incorporate this strategy neither in lesson planning nor in the student's task. Thus, both PSTs remained with factual knowledge.

From the above, it is concluded that the LS intervention contributed to improve the PCK-PK, of the PSTs, on the speed of sound to 8th graders in a specific classroom context. The exception was on Strategies to promote students examination of their own learning, since two PSTs (PST2 and PST3) remained with a median values $=2$ due to the LS intervention. 


\section{DISCUSSION}

As already referred, this research aimed to examine the effect of the LS - adjusted for the initial teacher education - in the development of the PSTs' PCK on a science topic. To pursue this aim two Research Questions were considered (section Introduction).

Regarding the RQ1, results revealed (Table 4), that PSTs' participation in the LS improved their PCK on the speed of sound. These results are in good agreement with the research conducted by Juhler (2016) and Can (2019) using LS in the initial PSTs training. In concrete, Juhler also found that the lesson planning in LS can stimulates the development of the PSTs' PCK, in which it was considered to include three of the four components (Knowledge of science curriculum, Knowledge of pupils' understanding of science, and Knowledge of instructional strategies) that the present paper also assumes as PCK's components. Can (2019) also concluded that the following three components of PCK of the PSTs Knowledge of science curriculum, Knowledge on students' understanding of specific science topics, and Knowledge of instructional strategies for teaching science, significantly improved after a LS. These components were also assumed to be part of the PCK in this investigation.

In the scope of the RQ2, as referred before, it was evaluated the changes on the specific aspects of the PCKTSK and PCK-PK (section Answer to the RQ2). The PCKTSK results revealed (Table 6) that the PSTs improved their knowledge of how to proceed or why in the teaching of the speed of sound on Depth, breadth, and accuracy of the topic knowledge (median $=2$ for each PSTs, before the LS, and 3 or 4, after the LS), Connections with NOS (median $=2$ for each PSTs, before the LS, and 3 or 4 , after the LS), and Fluency with multiple modes of representation (median $=2$ for each PSTs, before the LS, and 4, after the LS). However, for both aspects Depth, breadth, and accuracy of the topic knowledge and Connections with NOS, two of the PSTs (PST2 and PST3) did not reach the understanding of the importance of including both aspects in the teaching of the topic (since they only reached a median value of 3 after the LS). It is the authors' conviction that both PST2 and PST3 would need additional training namely to reinforce a more robust understanding of the importance of to work some variables (e.g., distance, time interval) and math operations (e.g., the division between two variables) in the teaching of the topic, as well as the importance of including elements of NOS in their teaching practice.

On the latter argument, Akerson et al. (2017) also found that although the PSTs in LS have given good suggestions about how to teach the NOS, at the primary level, they were not able to apply their suggestions in the classroom. These results obtained by Akerson et al. (2017) reveal the PSTs' difficulty to include NOS into their teaching practice in convergence with those obtained in the present investigation since two of the PSTs (PST2 and PST3, Table 6) also revealed not know the reason (why) to include NOS in the topic teaching after the LS (median=3). Therefore, reinforced attention should be paid to this knowledge during the implementation of the LS in an initial teacher training. Actually, the LS design to the initial training (e.g., number of sessions in the planning phase, duration of each session, number of LS cycles), structure of the sessions (e.g., materials), as well as the role of educators to support PSTs' learning is still scarce.

The PCK-PK results revealed (Table 6) that as a consequence of the lesson plan design, the observation of its enactment, in the Research Lesson, by an experienced $\mathrm{CT}$, and subsequent reflection on the implications of teaching strategies supported in the students' results, the PSTs improved their knowledge of how to proceed or why on the strategies of teaching the speed of sound. In particular, in relation to the Understanding how students' prior conceptions determine the instructional decisions, Rational linking teaching strategies to student learning, and Implications of teaching strategies based on students' results.

These results converge with those obtained by Nilsson and Loughran (2012) that also concluded that the PSTs' observation of classes and followed by reflection stimulate teachers to understand students' difficulties, as well as to identify the relationship of these difficulties with teaching strategies. In fact, students' outcomes and classroom situations provide insights to further enlighten new actions, thus representing leverage points to the PSTs' PCK-PK growth, as obtained in this research and proposed elsewhere (e.g., Carlson \& Daehler, 2019; Gess-Newsome, 2015).

As it is already mentioned, regarding the PSTs' PCKPK concerning the Strategies to promote students' selfevaluation aspect, the results revealed (Table 6) unsatisfactory improvement. Can (2019) concluded that PSTs' PCK on Assessment in science did not improve significantly, after the LS, namely on what and why to assess. These results are somehow convergent with what was found in this investigation since PST2 and PST3 revealed not know how to implement strategies to students' self-evaluation, and none of the three PSTs knew why this strategy is important to teach the topic. As such, these results seem to show that the PSTs need a specific support during the LS intervention to stimulate their knowledge on how students might become active participants in the process of teaching and learning, and why. Particularly, why to involve students' understanding of how they are learning, what they are learning and when they need more information, as suggested by the National Research Council (2001). 


\section{CONCLUSIONS}

From the current investigation, the following conclusions can be drawn:

- the LS in the initial training improved the PCK on a physics topic at $8^{\text {th }}$ grade of the three PSTs involved in the investigation, as revealed by the paired comparison of PSTs' PCK-pos (median) and the PCK-pre (median) using a descriptive statistical treatment Table 4)

- most of the aspects of both PCK components namely, the topic specific knowledge (PCK-TSK) and pedagogical knowledge (PCK-PK) also improved. In concrete, the PSTs improved, respectively, 3 aspects out of 3 of the PCK-TSK and 3 aspects out of 4 of the PCK-PK. The PCK-PK aspect Strategies to promote students' selfevaluation was the only one that did not satisfactorily improved.

The current investigation was performed using the LS with an adaptation (namely, the adjustment of the LS sessions' content to the previous PSTs' knowledge) and involving a small number of PSTs participants $(n=3)$. In addition, the LS implementation used a specific topic (in concrete, the speed of sound) that is taught to 8th grade students. Thus, the findings of this investigation are valid for the present results. The conclusions' generalization to a wider range of scientific topics (physics and chemistry) and for all PSTs may be, partially or totally, invalid.

\section{IMPLICATIONS}

This research contributed to deeper the knowledge of the PCK of PSTs in two senses: from the science educators' perspective since it highlights the feasibility of including the LS in the initial teacher programs and from the researchers' perspective since it concurs to increment the academic knowledge on the PCK development using LS in initial teacher education.

Future investigations will be guided in two main directions:

- Focusing on improving the understanding of the educators' role towards the LS success

- Deepening the understanding of the teaching practice on the PCK improvement thus, the PSTs will be giving the research lesson(s).

These findings suggest that LS should be carried out during the training programs of the science PSTs.

Author contributions: All authors have sufficiently contributed to the study, and agreed with the results and conclusions.

Funding: TC gratefully acknowledges the financial support of Foundation for Science and Technology - Portugal (FCT) under the Grant SFRH/BD/147648/2019.

Declaration of interest: No conflict of interest is declared by authors.

\section{REFERENCES}

Akerson, V., Pongsanon, K., Rogers, M., Carter, I., \& Galindo, E. (2017). Exploring the use of Lesson study to develop elementary preservice teachers' pedagogical content knowledge for teaching nature of science. International Journal of Science and Mathematics Education, 15(2), 293-312. https: / / doi.org/10.1007/s10763-015-9690-x

Baumert, J., Kunter, M., Blum, W., Brunner, M., Voss, T., Jordan, A., Klusmann, U., Krauss, S., Neubrand, M., \& Tsai, Y.-M. (2010). Teachers' mathematical knowledge, cognitive activation in the classroom, and student progress. American Educational Research Journal, 47(1), 133-180. https://doi.org/10.3102/ 0002831209345157

Baxter, J. A., \& Lederman, N. G. (1999). Assessment and measurement of pedagogical content knowledge. In J. A. Baxter \& N. G. Lederman (Eds.), Examining pedagogical content knowledge: The construct and its implications for science education (pp. 147-161). Kluwer.

Can, H. B. (2019) Learning science teaching by taking advantages of Lesson Study: An effective form of professional development. Journal of Educational Issues, 5(2), 150-169. https://doi.org/10.5296/ jei.v5i2.15497

Carlson, J., \& Daehler, K. (2019). The refined consensus model of pedagogical content knowledge in science education. In A. Hume, R. Cooper, \& A. Borowski (Eds.), Repositioning pedagogical content knowledge in teachers' knowledge for teaching science (pp. 77-92). Springer.

Clarke, A., Triggs, V., \& Nielsen, W. (2014). Cooperating teacher participation in teacher education: A review of the literature. Review of Educational Research, 84(2), 163-202. https://doi.org/10.3102/ 0034654313499618

Coe, R., Aloisi, C., Higgins, S., \& Major, L. E. (2014). What makes great teaching? Review of the underpinning research, Project Report. Sutton Trust. https: / / www .suttontrust.com/wp-content/uploads/2014/10/ What-Makes-Great-Teaching-REPORT.pdf

Coenders, F., \& Verhoef, N. (2019). Lesson study: professional development (PD) for beginning and experienced teachers. Professional Development in Education, 45(2), 217-230. https:/ / doi.org/10.1080/ 19415257.2018.1430050

Cohen, J. (1960). A coefficient of agreement for nominal scales. Educational Psychological Measurement, 20(1), 37-46.

https:/ / doi.org/10.1177/001316446002000104

Conceição, T., Baptista, M., \& Ponte, J. P. (2019). Lesson study as a trigger for preservice physics and chemistry teachers' learning about inquiry tasks and classroom communication. International Journal 
for Lesson and Learning Studies, 8(1), 79 96. http://www.scopus.com/inward/record.url? eid=2-s2.0 - 85059512923\&partnerID=MN8TOARS

Creswell, J. (2002). Educational research: Planning, conducting, and evaluating quantitative and qualitative research. Merrill Prentice Hall.

Danday, B. A. (2019). Active vs. passive microteaching Lesson Study: Effects on pre-service teachers' technological pedagogical content knowledge. International Journal of Learning, Teaching and Educational Research, 18(6), 181-200. https:/ / doi.org/10.26803/ijlter.18.6.11

De Jong, O., \& Van Driel, J. (2004). Exploring the development of student teachers' PCK of the multiple meanings of chemistry topics. International Journal of Science and Mathematics Education, 2(4), 477-491. https://doi.org/10.1007/s10763-0044197-x

Eshach, H., \& Schwartz, J. (2006). Sound stuff? Naïve materialism in middle school students' conceptions of sound. International Journal of Science Education, 28, 733-764. https://doi.org/10.1080/09500690500 277938

Eshach, H., Lin, T.- C., \& Tsai, C.-C. (2017). Misconception of sound and conceptual change: A cross-sectional study on students' materialistic thinking of sound. Journal of Research in Science Teaching, 55, 677-689. https://doi.org/10.1002/ tea.21435

Fujii, T. (2014). Implementing Japanese Lesson study in foreign countries: Misconceptions revealed. Mathematics Teacher Education and Development, 16(1), 65-83. https:/ / eric.ed.gov/?id=EJ1046666

Fujii, T. (2016). Designing and adapting tasks in lesson planning: a critical process of lesson study. ZDM Mathematics Education, 48(4), 411-423. https:/ / doi.org/10.1007/s11858-016-0770-3

Fujii, T. (2018). Lesson Study and teaching mathematics through problem solving: The two wheels of a cart. In M. Quaresma, C. Winsløw, S. Clivaz, J. Ponte, A. Ní Shúilleabháin, \& A. Takahashi (Eds.), Mathematics lesson study around the world (pp. 1-21). ICME-13 Monographs. Springer, Cham. https:/ / doi.org/10.1007/978-3-319-75696-7_1

Gess-Newsome, J. (2015). A model of teacher professional knowledge and skill including PCK. In A. Berry, P. Friedrichsen, \& J. Loughran (Eds.), Reexamining pedagogical content knowledge in science education (pp. 28-42). Routledge Press.

Gess-Newsome, J., Taylor, J., Carlson, J., Gardner, A., Wilson, C., \& Stuhlsatz, M. (2019). Teacher pedagogical content knowledge, practice, and student achievement. International Journal of Science Education, 41(7), 944-963. https:/ / doi.org/10.1080/ 09500693.2016.1265158
Grossman, P. (2010). Learning to practice: The design of clinical experience in teacher preparation. http:/ / citeseerx.ist.psu.edu/viewdoc/download;j sessionid $=$ EB8D8E854DC5DA839408832D45C8DF 24? doi=10.1.1.178.4088\&rep=rep1\&type=pdf

Hart, L. C., Alston, A. S., \& Murata, A. (2011). Lesson study research and practice in mathematics education. Springer. $\quad$ https://doi.org/10.1007/978-90-4819941-9

Huang, R., \& Shimizu, Y. (2016). Improving teaching, developing teachers and teacher educators, and linking theory and practice through lesson study in mathematics: an international perspective. ZDM Mathematics Education 48, 393-409. https:/ / doi.org/10.1007/s11858-016-0795-7

Jain, P., \& Brown, A. L. (2020). Using an adapted Lesson Study with early childhood undergraduate students, teaching education. Teaching Education, 121.

https:/ / doi.org/10.1080/10476210.2020.1826424

Juhji, J., \& Nuangchalerm, P. (2020). Interaction between scientific attitudes and science process skills toward technological pedagogical content knowledge. Journal for the education of gifted young scientists, 8(1), 1-16. https://doi.org/10.17478/ jegys.2020.XX

Juhler, M. V. (2016). The use of Lesson study combined with content representation in the planning of physics lessons during field practice to develop pedagogical content knowledge. Journal of Science Teacher Education, 27(5), 533-553. https: / / doi.org/10.1007/s10972-016-9473-4

Käpylä, M., Heikkinen, J., \& Asunta,T. (2009). Influence of content knowledge on pedagogical content knowledge: The case of teaching photosynthesis and plant growth. International Journal of Science Education, 31(10), 1395-1415. https://doi.org/ $10.1080 / 09500690802082168$

Kind, V. (2009). Pedagogical content knowledge in science education: Perspectives and potential for progress. Studies in Science Education, 45(2), 169-204. https:/ / doi.org/10.1080/03057260903142285

Kind, V. (2017). Development of evidence-based, student-learning-oriented rubrics for pre-service science teachers' pedagogical content knowledge. International Journal of Science Education, 41(7), 911943.

https:/ / doi.org/10.1080/09500693.2017.1311049

Kind, V., \& Chan, K. H. (2019). Resolving the amalgam: Connecting pedagogical content knowledge, content knowledge and pedagogical knowledge. International Journal of Science Education, 41(7), 964978.

https:/ / doi.org/10.1080/09500693.2019.1584931 
Korthagen, F., \& Kessels, J. (1999). Linking theory and practice: Changing the pedagogy of teacher education. Educational Researcher, 28(4), 4-17. https:/ / doi.org/10.3102/0013189X028004004

Krippendorff, K. (1980). Content Analysis: An Introduction to its Methodology. Sage Publications.

Larssen, D., Cajkler, W., Mosvold, R., Bjuland, R., Helgevold, N., Fauskanger, J., Wood, P., Baldry, F., Jacobsen, A., Bugge, H. E., Næsheim-Bjørkvik, G., \& Norton, J. (2018). A literature review of Lesson study in initial teacher education: Perspectives about learning and observation. International Journal for Lesson and Learning Studies, 7(1), 8-22. https:/ / doi.org/10.1108/IJLLS-06-2017-0030

Lederman, N. G., \& Gess-Newsome, J. (1992). Do subject matter knowledge, and pedagogical content knowledge constitute the ideal gas law of science teaching? Journal of Science Teacher Education, 3(1), 16-20. https:/ / doi.org/10.1007/BF02614732

Liepertz, S., \& Borowski, A. (2018). Testing the consensus model: Relationships among physics teachers' professional knowledge, interconnectedness of content structure and student achievement. International Journal of Science Education, 41(7), 890910.

https:/ / doi.org/10.1080/09500693.2018.1478165

Lim, C. S., Kor, L. K., \& Chia, H. M. (2016). Revitalising mathematics classroom teaching through Lesson Study (LS): a Malaysian case study. ZDM Mathematics Education 48, 485-499. https: / / doi.org/10.1007/s11858-016-0779-7

Loughran, J., Berry, A., \& Mulhall, P. (Eds.). (2012). Understanding and developing science teachers' pedagogical content knowledge (2nd ed.). Sense Publishers.

Loughran, J., Mulhall, P., \& Berry, A. (2004). In search of pedagogical content knowledge in science: Developing ways of articulating and documenting professional practice. Journal of Research in Science Teaching, 41(4), 370-391. https://doi.org/10.1002/ tea. 20007

Marble, S. (2007). Inquiry into teaching: Lesson study in elementary science methods. Journal of Science Teacher Education, 18(6), 935-953. https: / / doi.org/10.1007/s10972-007-9071-6

Munthe, E., Bjuland, R., \& Helgevold, N. (2016). Lesson study in field practice: a time-lagged experiment in initial teacher education in Norway. International Journal for Lesson and Learning Studies, 5(2), 142-154. https:/ / doi.org/10.1108/IJLLS-12-2015-0047

National Commission on Teaching \& America's Future (U.S.). (1996). What matters most: Teaching for America's future: report of the National Commission on Teaching $\mathcal{E}$ America's Future: summary report. National Commission on Teaching \& America's
Future.

https: / / files.eric.ed.gov/ fulltext/ED395931.pdf

National Research Council. (2001). Classroom Assessment and the National Science Education Standards. The National Academy Press. https:/ / doi.org/10.17226 /9847

Ni Shuilleabhain, A., \& Bjuland, R. (2019) Incorporating lesson study in ITE: organisational structures to support student teacher learning. Journal of Education for Teaching, 45(4), 434-445. https: / / doi.org/10.1080/02607476.2019.1639262

Nilsson, P. \& Karlsson, G. (2019). Capturing student teachers' pedagogical content knowledge (PCK) using CoRes and digital technology. International Journal of Science Education, 41(4), 419-447. https:/ / doi.org/10.1080/09500693.2018.1551642

Nilsson, P. (2008). Teaching for understanding: The complex nature of pedagogical content knowledge in pre-service education. International Journal of Science Education, 30(10), 1281-1299. https:/ / doi.org/10.1080/09500690802186993

Nilsson, P., \& Loughran, J. (2012). Exploring the development of pre-service science elementary teachers' pedagogical content knowledge. Journal of Science Teacher Education 23(7), 699-721. https:/ / doi.org/10.1007/s10972-011-9239-y

Perry, R. R., \& Lewis, C. C. (2009). What is successful adaptation of lesson study in the US? Journal of Educational Change, 10, 365-391. https://doi.org/ 10.1007 / s10833-008-9069-7

Robak, P., Chance, B., Legler, J., \& Moore, T. (2006). Applying Japanese lesson study principles to an upper-level undergraduate statistics course. Journal of Statistics Education, 14(2), 1-20. https:/ / doi.org/10.1080/10691898.2006.11910580

Sawada, D., Piburn, M. D., Judson, E., Turley, J., Falconer, K., Benford, R., \& Bloom, I. (2002). Measuring reform practices in science and mathematics classrooms: The reformed teaching observation protocol. School Science and Mathematics, 102(6), 245-253. https://doi.org/ 10.1111/j.1949-8594.2002.tb17883.x

Schön, D. A. (1983). The reflective practitioner: How professionals think in action. Basic Books.

Seperson, M. A. \& Joyce, B. R. (1971). The teaching styles of student teachers as related to the teaching styles of their cooperating teachers (ERIC Document Reproduction Service No. ED 051080).

Shulman, L. S. (1986). Those who understand: Knowledge growth in teaching. Educational Researcher, 15(2), 4-14. http://links.jstor.org/sici? sici $=0013-189 X \% 28198602 \% 2915 \% 3$ A2\%3C4\%3AT WUKGI\%3E2.0.CO\%3B2-X 
Sorge, S., Kröger, J., Petersen, S., \& Neumann, K. (2017). Structure and development of pre-service physics teachers' professional knowledge. International Journal of Science Education 41(7), 862-889. https: / / doi.org/10.1080/09500693.2017.1346326

Stigler, J. W., \& Hiebert, J. (1999). The teaching gap. Free Press.

Takahshi, A. \& McDowel, T. (2016). Collaborative lesson research: Maximizing the impact of lesson study. ZDM Mathematics Education 48, 513-526. https: / / doi.org/10.1007/s11858-015-0752-x

Uşak, M. (2009). Preservice science and technology teachers' pedagogical content knowledge on cell topics. Educational Sciences: Theory E Practice, 9(4),
2033-2046.

https:/ / files.eric.ed.gov/fulltext/EJ867376.pdf

Van Driel, J. H., \& Berry, A. (2012). Teacher professional development focusing on pedagogical content knowledge. Educational Researcher, 41(1), 26-28. https://doi.org/10.3102/0013189X11431010

Van Driel, J. H., de Jong, O., \& Verloop, N. (2002). The development of pre-service chemistry teachers' pedagogical content knowledge. Science Education, 86(4), 572-590. https:/ / doi.org/10.1002/ sce.10010

Zanting, A., Verloop, N., Vermunt, J. D., \& Van Driel, J. H. (1998). Explicating practical knowledge: An extension of mentor teachers' roles. European Journal of Teacher Education, 21(1), 11-28. https:/ / doi.org/10.1080/0261976980210104

\section{http://www.ejmste.com}

